\title{
GCU
}

Glasgow Caledonian

University

University for the Common Good

\section{Enhanced low-cost web-based virtual tour experience for prospective students}

Insa Iglesias, Maria; Jenkins, Mark; Morison, Gordon

Published in:

2021 IEEE Conference on Virtual Reality and 3D User Interfaces Abstracts and Workshops

DOI:

10.1109/VRW52623.2021.00221

Publication date:

2021

Document Version

Author accepted manuscript

Link to publication in ResearchOnline

Citation for published version (Harvard):

Insa Iglesias, M, Jenkins, M \& Morison, G 2021, Enhanced low-cost web-based virtual tour experience for prospective students. in 2021 IEEE Conference on Virtual Reality and 3D User Interfaces Abstracts and Workshops . IEEE, pp. 677-678, 28th IEEE Conference on Virtual Reality and 3D User Interfaces, 27/03/21. https://doi.org/10.1109/VRW52623.2021.00221

\section{General rights}

Copyright and moral rights for the publications made accessible in the public portal are retained by the authors and/or other copyright owners and it is a condition of accessing publications that users recognise and abide by the legal requirements associated with these rights.

Take down policy

If you believe that this document breaches copyright please view our takedown policy at https://edshare.gcu.ac.uk/id/eprint/5179 for details of how to contact us. 


\title{
Enhanced Low-cost Web-based Virtual Tour Experience for Prospective Students
}

\author{
Maria Insa Iglesias* $\quad$ Mark Jenkins $^{\dagger} \quad$ Gordon Morison \\ Glasgow Caledonian University, Glasgow, United Kingdom
}

\begin{abstract}
This paper presents a web-based Virtual Tour (VT) pipeline to allow organisations to develop a VT experience rapidly, which integrates a collaborative virtual environment with avatars and a 3D Environment to provide visitors an interactive and shareable experience. Users from an organisation with minimal coding experience can develop a low-cost web-based VT using a 360 camera, the Open Source tools Marzipano and Hubs, the developed software framework and documentation directly from the GitHub repository. The contribution of this work is both the software framework for use with the Marzipano, Mozilla Hubs tool and Tin Can API. A University case study along with a user evaluation demonstrate the effectiveness of the approach.
\end{abstract}

Index Terms: Human-centered computing-Human computer interaction (HCI) - Interaction paradigms - Web-based interactionCollaborative interaction; Information systems-Information systems applications-Collaborative and social computing systems and tools-Open source software

\section{INTRODUCTION}

With the outbreak of Covid-19, the use of internet has exploded, and educational institutions have transformed face-to-face events into an online format. Like Glasgow Caledonian University (GCU), many universities have joined online platforms to run lectures and staff meetings, as well as, promotional events such as open days to recruit future student.

Although virtual open days are still a great option to explore what the University has to offer, students cannot experience a walk around the University facilities. As a result, many Universities have included a Virtual Tour (VT) to their website providing a 360degrees experience of their Campus. This allow students to evaluate University campuses navigating through a 360-degrees experience of the teaching facilities, student rooms and shared open spaces [4]. This can positively influence student application decisions, making campus tours one of the best tool for recruiting prospective students.

There are many companies [1] dedicated to developing VTs or teaching users methods to create them [5], however these solutions can be very expensive. There are cheaper solutions like developing 360 VT with Google VR Tour Creator, Panellum, Roundme or kprano, but these tools provide limited functionality or requires purchasing a license to obtain the complete functionality. To the best of our knowledge, Marzipano [3] is the only Open Source tool that allows the design, development and customisation of VTs, although it requires programming skills in JavaScript, HTML and CSS.

This paper proposes a web-based VT pipeline that allows users, who have minimal coding experience, to develop a low-cost webbased VT experience that can compete in functionality with sophisticated VTs created by experts. The pipeline proposes guidance to

\footnotetext{
*e-mail: maria.insaiglesias@gcu.ac.uk

†e-mail: mark.jenkins@gcu.ac.uk

†e-mail: gordon.morison@gcu.ac.uk
}

develop a web-based 360 Virtual Tour using a JavaScript API called Marzipano and implementing the software framework published ${ }^{1}$ as part of the contribution. The HTML, JavaScript and CSS software framework developed integrates extra functionality to the VT proposed by Marzipano Tool by (i) incorporating a shared virtual environment with $\mathrm{Hubs}^{2}$, (ii) integrating the Tin Can API to collect data about audience's activity, and (iii) complying to the Web Content Accessibility Guidelines (WCAG). Following the method proposed, a case study is presented: "360 Virtual Tour Experience of GCU - Glasgow Campus" ${ }^{3}$. This work enables Universities and other organisations to stay competitive within the evolving landscape embracing 360 VT technology, and distinguish from its competitors by integrating a private virtual meeting space.

\section{Virtual tour Pipeline}

This sections provides an overview of the Open Source pipeline to develop a low-cost web-based VT experience using a 360 camera, Marzipano, Mozilla Hub and Learning Record Store (LRS) account. The pipeline proposed consists of the following phases: Research, Planning, Design and Development, Hosting and Feedback (described into detail in [2]). The Design and Development stage involves the software framework implementation. Taking such work [2] as baseline, this paper proposes an enhanced software framework (see Fig.1(left)) with extensive additional functionality to the initially proposed and full user documentation ${ }^{4}$.

Fig.1(left) shows a data flow diagram to allow users understand the implementation of the framework implementation to develop their VT. First of all, users requires to download and extract files from the GitHub Repository framework, named "Organization_Virtual_Tour" folder in Fig.1. Second, the framework Fig.1(middle) is edited with the organisation VT files, named "Marzipano_Virtual_Tour" folder in Fig.1, obtained creating the VT with Marzipano Tool. Third, the LRS account is created and set up in the corresponding file from the "Organization_Virtual_Tour" folder. After, the VT is hosted and linked to the collaborative 3D environment created with Mozilla Hubs.

\section{Virtual Tour Experience of GCU}

This section presents the "360 Virtual Tour Experience of GCU Glasgow Campus", a case study that demonstrates the applicability of the 360-degrees VT pipeline proposed. The 360 Virtual Tour Experience that consist of: Collaborative 3D Campus Environment and 360-degree Virtual Tour.

Collaborative 3D Environment - On running the VT, a windows pops up (see Fig.1(a)) where students need to type their their name and paste the Mozilla Hub link shared with them previously. This will provide them access to the shared virtual space (see Fig.1(b)), a simplified 3D model of the main Campus buildings. Student ambassadors and prospective students are immersed in this

\footnotetext{
${ }^{1}$ https://github.com/Insa-Maria/Virtual_Tour.git

${ }^{2} \mathrm{https}: / /$ hubs.mozilla.com/spoke/

${ }^{3}$ https://campus.gcu.ac.uk/

${ }^{4}$ https://github.com/Insa-Maria/Virtual_Tour/blob/master/ documentation/Documentation.pdf
} 

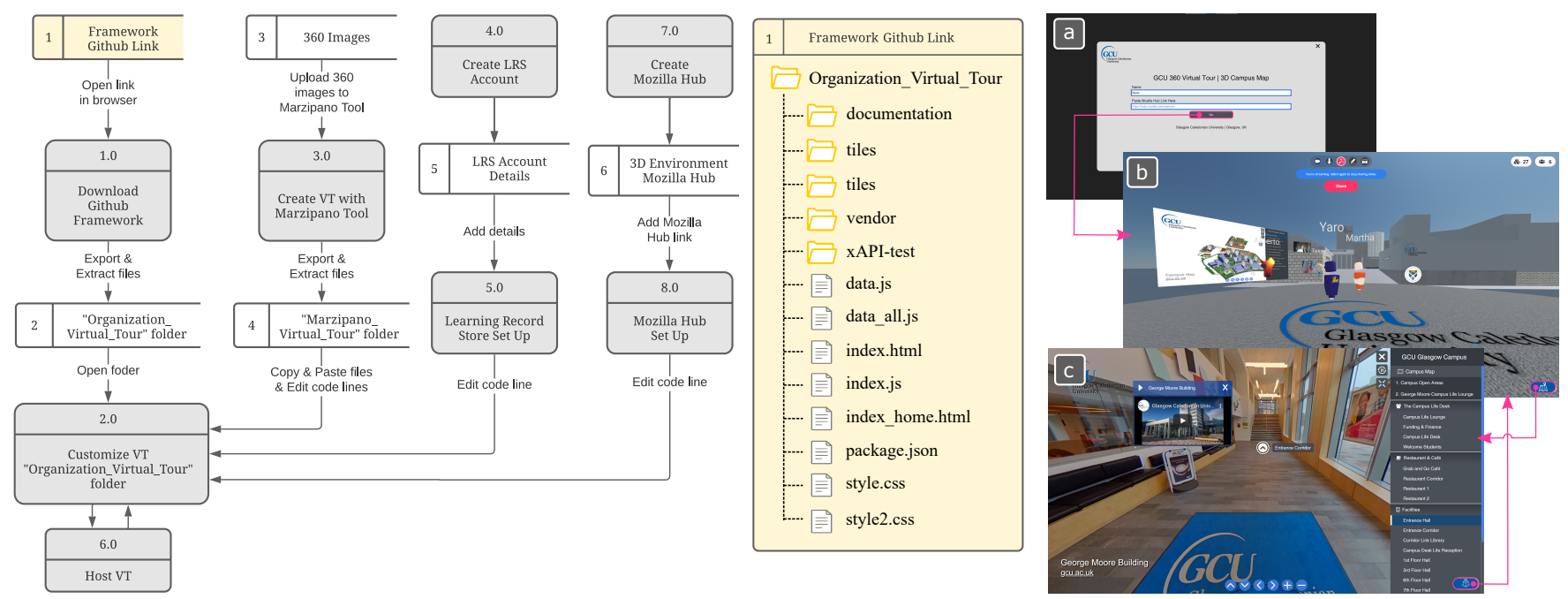

Figure 1: The software framework consist of the shown folder and files, which are edited or replaced following the documentation and Data Flow Diagram (left). The "360 Virtual Tour Experience of GCU - Glasgow Campus" consist of: Collaborative 3D Campus Environment (b) and 360-degree Virtual Tour (c).

environment using costumed avatars. This environment allow students, who are registered to the Virtual Open Day session, meet and interact virtually using chat, cam or microphone, if desired. This shared space is the meeting point where student ambassadors start the virtual walking tour around Campus Building. From this environment, students also have access to the 360 Virtual Tour of GCU that will be open on a new tab when students click on it.

360-degree Virtual Tour - The 360 Virtual Tour of GCU provides (Fig.1(c)) a 360-degrees view of the teaching facilities, library, student rooms and shared open spaces, among others. This webbased VT is designed to allow prospective student freely explore the environment. This page is enhanced with the integration of an Open Source API, called Tin Can API, into 360 images to allow the University collecting data about visitor's activity during their VT experience. This API feeds the LRS, which provide a dashboard to monitor visitors'activity, and therefore track the most frequently visited facilities, for example.

Design Process - When Covid-19 pandemic started, GCU's Department of Computing reassessed their goals for the academic year and designed a plan to invest in a 360 camera to develop a collaborative virtual experience where future students meet and interact virtually with students ambassadors. This way, student students ambassadors would be able to guide them through the facilities of the Glasgow campus and help students to gain a better perspective of the campus in these times where open days are online.

Several online meetings with staff were run to agree on, among other aspects, the following functional requirements [2]). On the first phase, the additional functionality implemented consisted on (i) a 2D Campus map that provides an overview of the Glasgow Campus building, (ii) video hotpots that introduces media content relevant to the environment, and (iii) Accessible Dropdown Menu that provides subgroup on the vertical menu. This first phase was developed in four weeks [2] and, after the successful launch of the 360 VT of GCU, a feedback session was run with the Marketing and Recruitment manager, who said: "The campus tour is working fantasticaly" and explained how students ambassadors run live virtual tour session. However, it was missing the interaction of student ambassadors with prospective students.

On the second phase, the additional functionality consisted on developing a collaborative environment to allow users interaction. This was integrated with Mozilla Hubs - Spoke Open Source tool, which is integrated in the VT creating an additional HTML file (called "index home.html" in Fig.1(middle)) that includes a code line with the link of the Mozilla Hubs created. In addition, the Tin Can API with LRS was integrated to allow the University gain a better understanding of the students activity in the website. This was possible adding a set of files to the framework, functions to the "index.js" file along with the LRS account details.

\section{Discussion AND Conclusion}

The contribution of paper is a 360-degrees VT pipeline that allows organisations to quickly develop a low-cost web-based VT experience, just investing in purchasing a 360 camera and paying a small monthly fee for other aspects (i.e. web hosting). The case study "360 Virtual Tour Experience of GCU - Glasgow Campus" can demonstrate the applicability of the pipeline. This would enable many Universities to provide a 360-degrees experience of a Campus visit, similarly to face-to-face open days, and being able to be at the same level to their competitors.

The proposed paper is a work-in-progress. It has been proved how the iterative design and feedback process has resulted in an enhanced experienced to deliver a more realistic experience to allow students to evaluate University destinations [2]. Further feedback is required on the last functionality implemented related to Mozilla Hubs and further work is required on the integration of the Tin Can API to allow organisation to obtain detailed data about the audience preferences.

\section{REFERENCES}

[1] 3DVista. Virtual tours, $360^{\circ}$ video and vr software, 2015. https://www.3dvista.com/ Last accessed on 2020-08-28.

[2] M. Insa-Iglesias, M. D. Jenkins, and G. Morison. Rapid development of a low-cost web-based 360 virtual tour. In Proc. Web Information Systems and Technologies (WEBIST), 1:315-322, nov 2020. doi: 10. 5220/0010176703150322

[3] Marzipano. 360 media viewer for the modern web, 2015. https://www.marzipano.net/ Last accessed on 2020-08-28.

[4] J. Shen, Y. Wang, C. Chen, M. R. Nelson, and M. Z. Yao. Using virtual reality to promote the university brand: When do telepresence and system immersion matter? vol. 26, pp. 362-393. Taylor \& Francis, 2020. doi: $10.1080 / 13527266.2019 .1671480$

[5] Virtual Tour Pro. Get paid for your virtual tours, 2019. https://www.virtualtourpro.com/ Last accessed on 2020-08-28. 